\title{
Effects of 12 months of detraining on health-related quality of life in patients receiving hemodialysis therapy
}

\author{
Clara Suemi Costa Rosa ${ }^{1,2}$. Christoforos D. Giannaki ${ }^{4} \cdot$ Argyro Krase $^{3} \cdot$ Meropi Mplekou $^{3} \cdot$ Stefania S. Grigoriou ${ }^{3}$. \\ loannis Stefanidis ${ }^{5}$. Eleftherios Lavdas ${ }^{6} \cdot$ Aggelos Pappas $^{3}$. Saul Bloxham ${ }^{7}$. Christina Karatzaferi ${ }^{3}$. \\ Giorgos K. Sakkas ${ }^{3,8}$ (D)
}

Received: 13 April 2020 / Accepted: 29 June 2020 / Published online: 14 August 2020

(c) Springer Nature B.V. 2020

\begin{abstract}
Purpose Limited data exist regarding the effects of detraining on functional capacity and quality of life (QoL) in the hemodialysis population. The aim of the current study was to assess whether the discontinuation from a systematic intradialytic exercise training program will affect aspects of health-related $\mathrm{QoL}$ and functional capacity in hemodialysis patients.

Methods Seventeen hemodialysis patients (12 Males/5 Females, age 60.8 \pm 13.6 year) participated in this study. Patients were assessed for functional capacity using various functional capacity tests while QoL, daily sleepiness, sleep quality, depression and fatigue were assessed using validated questionnaires at the end of a 12-month aerobic exercise program and after 12 months of detraining.

Results The detraining significantly reduced patients' QoL score by $20 \%(P=0.01)$. More affected were aspects related to the physical component summary of the QoL $(P<0.001)$ rather than those related to the mental one $(P=0.096)$. In addition, the performance in the functional capacity tests was reduced $(P<0.05)$, while sleep quality $(P=0.020)$ and daily sleepiness scores $(P=0.006)$ were significantly worse after the detraining period. Depressive symptoms $(P=0.214)$ and the level of fatigue $(P=0.163)$ did not change significantly.

Conclusions Detraining has a detrimental effect in patients' QoL, functional capacity and sleep quality. The affected physical health contributed significantly to the lower QoL score. It is crucial for the chronic disease patients, even during emergencies such as lockdowns and restrictions in activities to maintain a minimum level of activity to preserve some of the acquired benefits and maintain their health status.
\end{abstract}

Keywords Hemodialysis · Exercise training · Detraining · Quality of life

\section{Introduction}

End stage renal disease (ESRD) is often associated with various comorbidities such as hypertension, diabetes mellitus and cardiovascular disease, as well as with increased

Giorgos K. Sakkas

gsakkas@uth.gr

1 Bioscience Institute, Sao Paulo State University, Rio Claro, Brazil

2 CAPES Foundation, Ministry of Education of Brazil, Brasília, Brazil

3 Department of PE and Sport Science, University of Thessaly, Trikala, Greece

4 Department of Life and Health Sciences, University of Nicosia, Nicosia, Cyprus morbidity and mortality [1]. In addition, several studies have shown that the vast majority of hemodialysis patients suffer from significant impaired quality of life (QoL) and physical inactivity [2-4].

5 Department of Medicine, School of Health Science, University of Thessaly, Larissa, Greece

6 Department of Biomedical Sciences, University of West Attica, Athens, Greece

7 School of Sports, Health and Wellbeing, Plymouth Marjon University, Plymouth, UK

8 School of Sports and Health Sciences, Cardiff Metropolitan University, Cardiff, UK 
In the last years many studies reported that regular exercise, both aerobic and resistance training, is safe and beneficial to ESRD patients, including patients on hemodialysis $[5,6]$. Findings from exercise trials have demonstrated significant benefits in psychological aspects (such as depression symptoms, confidence, sense of independence) and functional capacity (ability to perform daily activities) for this patient's population [5, 7-13]. Nonetheless, it is postulated that exercise improves sleep disturbances of hemodialysis patients and, consequently QoL aspects [14].

However, many clinical exercise programs in hemodialysis units are not part of the usual treatment of ESRD patients, mostly of them are run on low budgets with partial or no financial support from the national health care systems and have limited duration often leading to large periods of program's discontinuation [15]. In addition, factors that may influence the participation of ESRD patients in systematic exercise training programs may include lack of motive to exercise, need of personalized exercise program, nurses' lack of encouragement to exercise, transportation issues and usage of exercise equipment during the hemodialysis session issues $[15,16]$. Moreover, a recent study on hemodialysis patients recognizes factors such as fatigue and pain feelings in both hemodialysis and non-hemodialysis days, other medical problems, fear for injury and unwillingness for exercise as significant barriers towards physical activity [17]. Of interest is the outcome of the same study that healthcare staff's negative attitudes toward exercise and physical activity of the patients was strongly associated with the low physical activity status of the patient.

If on one hand the physical exercise on hemodialysis patients promotes morphological, physiological and functional benefits, the time required keeping these improvements after the training interruption remains unclear. This interruption also known as detraining could lead to partial or complete loss of adaptations and performance induced by training and vary depending on quantity and quality of the pause period. Indeed, the findings of a recent pilot study reveal that detraining (discontinuation of exercise training for 10 months) could result in a significant loss of the previously gained functional capacity as assessed by the six-minute walk test [18]. However, it is still unclear whether detraining could lead to significant reductions in various other functional capacity (i.e. lower limb muscle strength) and quality of life aspects in the hemodialysis patients.

Thus, the aim of the present study was to investigate whether the discontinuation and long- term withdrawal from a systematic intradialytic exercise training program affects aspects of health-related QoL, sleep quality, fatigue, depression and functional capacity in patients receiving hemodialysis therapy.

\section{Materials and methods}

\section{Participants}

Seventeen hemodialysis patients ( 12 Males/5 Females, age $60.8 \pm 13.6$ year) previously recruited to participate on 12 months of intradialytic exercise training program from the dialysis unit at the General Hospital of Trikala, Greece. Patients who completed a 12-month intradialytic aerobic exercise program included in this study. Entry criteria included also being on chronic hemodialysis for 6 months or more with adequate dialysis efficacy (Kt/V more than 1.3). Patients were excluded if they did not complete the 12 months intradialytic exercise training program. During the 12 months detraining period, none of the recruited patients were hospitalized for any reason. All patients gave informed consent prior to study participation. The study was approved by the Ethics Committee on Human Research at the University of Thessaly, Greece.

\section{Study design}

Patients were studied at the General Hospital of Trikala, Greece, using validated questionnaires and functional tests at the end of a 12-month of intradialytic aerobic (cycling) exercise program using a Monark cycle ergometer (Monark, Sweden) and at 12 months of detraining. The exercise training program consisted by 3 sessions per week $/ 45$ min each session at an intensity between $60-65 \%$ of the patient's maximal capacity of exercise. Maximal capacity of exercise was evaluated by an incremental cycle ergometry test to volitional exhaustion. The questionnaire materials were completed with interview methods by experienced personnel.

\section{Questionnaires}

The SF-36 questionnaire [19] was used for the assessment of the QoL levels of the patients. Daily sleepiness was assessed by the Epworth sleepiness scale [20]. The Zung self-rating depression scale was used to assess the subjective depression score [21]. Quality of sleep was estimated using a 7-day sleep diary using Weekly Sleep Questionnaire. The sleep diary contained questions about how often during the previous week dialysis patients experienced any of the following: (1) difficulties falling asleep, (2) number of nocturnal awakenings, (3) difficulties remaining asleep, (4) the sensation of waking-up tired and fatigued, (5) day time stress and (6) how often did they feel refreshed after the night's sleep. The sleep diary scored as: 'never' (0 points), ' $1-2$ times a week' ( 1 point), ' $3-5$ times a week' ( 2 points), ' $6-7$ times a week' ( 3 points). For question number 6 the scoring 
was reversed with 3 points for the answer 'never', and 0 points for the answer ' $6-7$ times a week'. The sleep diary score was calculated as the sum of the total points with the minimum at zero points and the maximum score at 18 [22]. Fatigue severity was assessed by the Fatigue Severity Scale (FSS) [23]. We should note that all the questionnaires used in the present study are commonly used in patients receiving hemodialysis therapy.

\section{Functional capacity assessment}

The patient's functional capacity was assessed by two sit-tostand (STS) tests: the STS-5 (the time taken to complete 5 sit-to-stand-to-sit cycles) and the STS60 (number of sit-tostand-to-sit cycles in $60 \mathrm{~s}$ ), and the fast walk test (measured the time spent to walk as fast as possible $6.06 \mathrm{~m}$ distance) $[24,25]$.

\section{Statistical analysis}

All data are presented as means $\pm \mathrm{SD}$. Paired $t$ tests were used to identify differences between all variables at the end of a 12-month of intradialytic aerobic exercise program and at 12 months of detraining. All analyses were carried out using the statistical package SPSS 17. P $<0.05$ was considered statistically significant. Hedge's bias corrected relative effect size and was calculated for all comparisons. Effect sizes were rated according to the conventions of Cohen as small $(0.20)$, moderate $(0.50)$, or large $(0.80)$.

\section{Power analysis}

Power analysis was performed using the open source software $G^{*}$ Power (3.1.9.2) and was used to calculate the achieved power with the current number of participants. A Post-hoc analysis revealed that in two of the main parameters related to the aims of the study (STS60 and QoL Total score) showed enough power to detect statistical significant differences between the two paired groups (within groups STS60: Effect size $d z=0.7104198$, sample size $N=17, D f=16$, Critical $t=2.1199053$, Power $(1-\beta$ err prob $)=0.7104198$; within groups QoL Total Score: Effect size $d z=0.8806118$, sample size $N=17, D f=16$, Critical $t=2.1199053$, Power $(1-\beta$ err prob) $=0.9258608)$.

\section{Results}

Characteristics (including age, body mass index-BMI \& years of dialysis) of the patients who followed the intradialytic exercise program for 12 months are presented in Table 1. Functional capacity (Fig. 1) and various SF-36 QoL questionnaire- derived scales decreased after 12 months of
Table 1 Patient characteristics

\begin{tabular}{ll}
\hline$N$ & 17 \\
Male/Female & $12 / 5$ \\
Age, $\mathrm{yr}$ & $60.8 \pm 13.6$ \\
$\mathrm{BMI}\left(\mathrm{kg} / \mathrm{m}^{2}\right)$ & $26.3 \pm 3.9$ \\
Years of dialysis & $7.4 \pm 4.1$ \\
\hline Data are mean $\pm \mathrm{SD}$ \\
BMI body mass index
\end{tabular}

detraining (Table 2). In particular, the time required to complete the STS- 5 increased by $22 \%$, the number of repetitions on STS60 decreased by $21 \%$ and time to complete the walking test increased by $15 \%$ with all differences showed moderate to large effect size. For the QoL questionnaire, physical function domain decreased by $33 \%(P<0.001)$, role function by $42 \%(P=0.004)$, body pain increased by $26 \%$ $(P=0.006)$, general health decreased by $21 \%(P=0.042)$ and vitality decreased by $26 \%(P=0.003)$, most of variables showed large effect size $(>0.80)$. The variables related to mental health [social function, role emotional and mental health, with the exception to vitality (which decreased by $25 \%, P=0.003)]$ showed reduced tendency but not statistically significant. Overall, physical health component summary which includes physical function, physical role, body pain and general health decreased significantly by $29 \%(P<0.001$, with large effect size $)$. On the other hand, mental health component summary which includes vitality, social functioning and role emotional, despite the fact that appeared decreased by $10 \%$, this difference did not reach statistical significance levels $(P>0.05$, with small effect size). The total score of QoL, was statistically significant decreased by $19 \%(P=0.001$, with large effect size $)$ after 12 months of detraining.

Also, 12 months of detraining affect sleep quality. Sleep diary questionnaire indicated significant reduction by $47 \%$ $(P=0.020)$ whereas daytime sleepiness increased significantly by $69 \%(P=0.006)$, both with large effect size. Moreover, Zung Self-Rating Depression scale and fatigue severity scale showed a non-statistical significant tendency to decrease after the detraining period $(P>0.05$, small effect size) (Table 2).

\section{Discussion}

It has been shown that absence of any systematic and organized aerobic exercise training for 12 months reduces significantly many aspects of health-related quality of life including functional capacity and sleep quality in ESRD patients receiving hemodialysis therapy. On the other hand, depressive symptoms, subjective fatigue and mental parameters of 


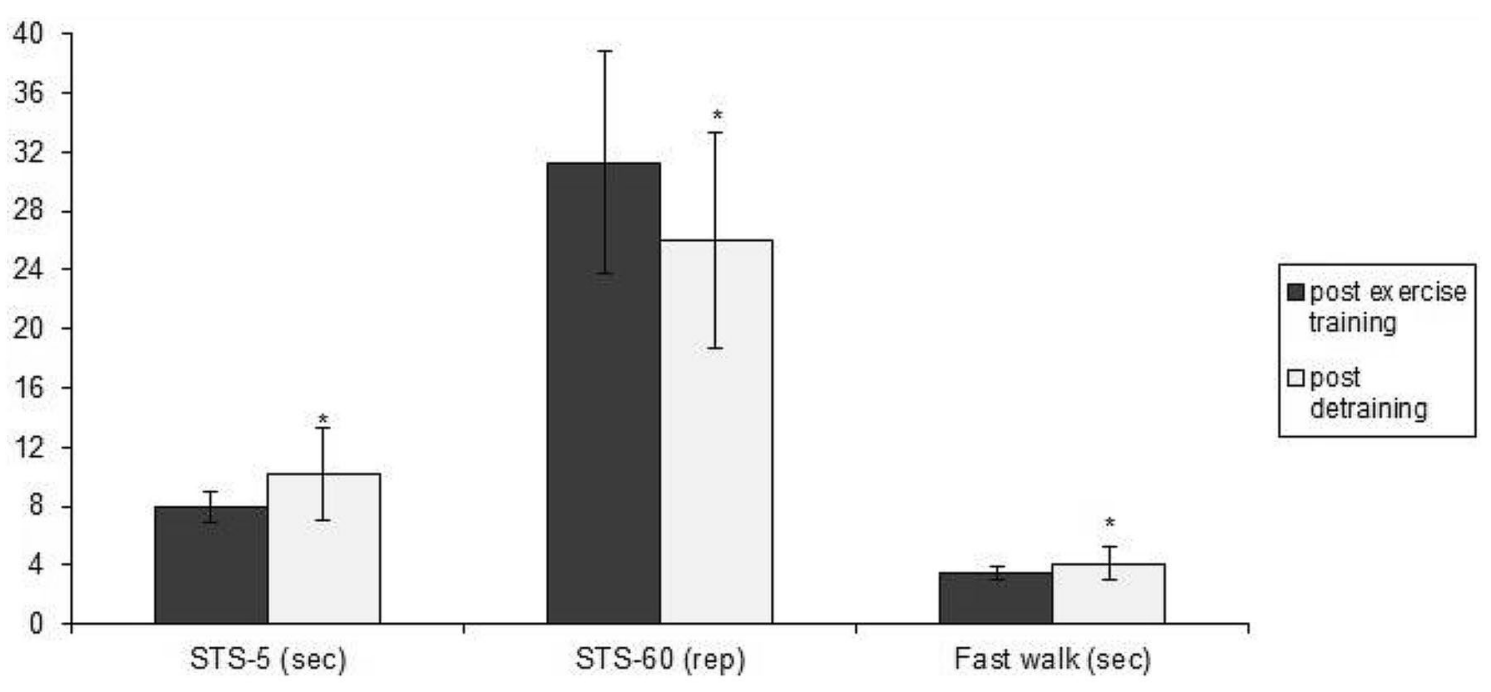

Functional Capacity

Fig. 1 Functional capacity at the end of exercise training program and following 12 months of detraining. Data are mean \pm SD. *Significantly different from the respective baseline value. STS sit-to-stand

Table 2 Functional capacity, quality of life, fatigue severity, sleep quality and depression at the end of exercise training program and following 12 months of detraining

\begin{tabular}{lccrc}
\hline Variables & Exercise & Detraining & $p$ value & ES \\
\hline Functional capacity* & & & & \\
STS-5 (seconds) & $7.96 \pm 1.03$ & $10.18 \pm 3.17$ & $\mathbf{0 . 0 1 4}$ & $\mathbf{0 . 9 1 2}$ \\
STS60 (repetitions) & $31.33 \pm 7.69$ & $26.00 \pm 7.30$ & $\mathbf{0 . 0 0 3}$ & $\mathbf{0 . 6 8 8}$ \\
Fasting walking (seconds) & $3.49 \pm 0.064$ & $4.12 \pm 1.11$ & $\mathbf{0 . 0 2 0}$ & $\mathbf{0 . 6 7 3}$ \\
SF-36 quality of life & & & & \\
Physical function & $87.33 \pm 16.99$ & $58.67 \pm 25.67$ & $<\mathbf{0 . 0 0 1}$ & $\mathbf{1 . 2 9}$ \\
Role function & $80.00 \pm 33.00$ & $46.67 \pm 42.12$ & $\mathbf{0 . 0 0 4}$ & $\mathbf{0 . 8 6}$ \\
Body pain & $88.87 \pm 17.65$ & $65.73 \pm 27.66$ & $\mathbf{0 . 0 0 6}$ & $\mathbf{0 . 9 7}$ \\
General health & $64.67 \pm 17.59$ & $51.13 \pm 23.81$ & $\mathbf{0 . 0 4 2}$ & $\mathbf{0 . 6 3}$ \\
Vitality & $71.33 \pm 17.97$ & $53.00 \pm 22.58$ & $\mathbf{0 . 0 0 3}$ & $\mathbf{1 . 4 0}$ \\
Social functioning & $85.93 \pm 21.94$ & $83.47 \pm 20.40$ & 0.708 & 0.11 \\
Role emotional & $82.20 \pm 33.07$ & $77.73 \pm 34.97$ & 0.632 & 0.13 \\
Mental health & $72.27 \pm 15.45$ & $71.73 \pm 14.30$ & 0.894 & 0.04 \\
Physical health & $77.67 \pm 16.91$ & $54.93 \pm 21.57$ & $<\mathbf{0 . 0 0 1}$ & $\mathbf{1 . 1 5}$ \\
Mental health & $74.80 \pm 14.70$ & $67.47 \pm 17.28$ & 0.096 & 0.45 \\
Total & $78.73 \pm 15.19$ & $63.53 \pm 18.77$ & $\mathbf{0 . 0 0 1}$ & $\mathbf{0 . 8 7}$ \\
Fatigue severity scale & & & & \\
FSS & $4.47 \pm 1.33$ & $4.83 \pm 1.45$ & 0.163 & 0.25 \\
Pittsburgh sleep quality index & & & & $\mathbf{0 . 0 2 0}$ \\
Sleep diary & $5.27 \pm 1.94$ & $7.73 \pm 3.58$ & $\mathbf{0 . 8 3}$ \\
Epworth & $6.40 \pm 3.56$ & $10.80 \pm 6.46$ & $\mathbf{0 . 0 0 6}$ & $\mathbf{0 . 8 2}$ \\
Zung self-rating depression scale & $37.47 \pm 7.63$ & $33.60 \pm 9.87$ & 0.214 & 0.43 \\
\hline
\end{tabular}

Data are mean \pm SD

Statistically significant $p$ values are in bold $(p<0.05)$

STS sit-to-stand; SF-36 short-form quality of life survey; FSS fatigue severity scale

*Significantly different from the respective baseline value 
QoL did not significantly change after 12 months of detraining despite the deterioration of those values.

It is well established that intradialytic exercise training improves many aspects of QoL and overall health in hemodialysis patients [5, 6]. Benefits include improvement in physical performance and functional capacity indices, physiological and biochemical adaptations and many psychological and mental health benefits for patients who participate in systematic exercise training programs $[5,6,26]$. On the other hand, in situations like COVID 19 lockdown where the cessation of exercise training is possible, it could result to a significant loss of the previously obtained beneficial adaptations affecting all aspects of health and reducing QoL levels to even below the pre-exercise participation levels, which are usually very low due to the burden of the disease [18].

Patients with chronic diseases should follow an active lifestyle through their lives on a longitudinal level to improve or maintain as possible their functionality level and QoL [27]. However, there is a notorious controversy regarding the required absence time from any systematic exercise training to lose all the acquired adaptations. The vast majority of the published studies on "detraining effect" (or reduction in exercise training volume) on physical performance, body composition and skeletal muscle physiology and biochemistry, involved athletes and physically-active populations [28, 29], whilst data are available also from bed rest studies [30] and studies on astronauts [31]. Briefly, these findings report significant reductions in cardiorespiratory capacity [29], muscle strength and power, alternations in muscle fiber type (i.e. from IIa to IIx) [32] and changes in enzyme content and mitochondrial-related parameters within the skeletal muscle $[33,34]$, reductions in muscle mass and increases in fat mass [28] and changes in blood lipids profile [28].

However, as exercise is finally considered an effective approach in managing symptoms and disease burden in patients with chronic conditions, detraining data are limited. For instance, reports over stroke patients [35], older people [36] and chronic obstructive pulmonary disease patients [37] have demonstrated detraining negative effects over time in functional capacity and strength levels. Notably, the decrease in various physical performance and functional capacity parameters could appear even within a few months of absence of training [38].

Among hemodialysis populations, the available published data on detraining effect on physiological parameters are limited. For instance, Mustata et al. demonstrated that one-month detraining following 3 months of aerobic exercise, reverted arterial stiffness to pre-exercise levels [39]. Moreover, only one study examined the effects of long-term detraining periods (10 months) in hemodialysis patients [18]. It seems that the magnitude of the impact depends on the percentage of reduction in physical activity, at least in the healthy populations [40]. It seems that it's crucial for the chronic disease patients, even during emergency situations such as lockdowns and restrictions in activities to maintain a minimum level of activity to preserve some of the acquired benefits.

The capacity of fast walking appeared significantly impaired after the 12 months of detraining. This is in line with other studies in non-ESRD populations, which reported that gait speed was the most affected parameter after a detraining period [41]. Moreover, the current study presents novel findings about the negative effect of detraining on lower extremities muscle endurance and strength of hemodialysis patients as assessed by the sit-to-stand tests. Changes in strength levels have been reported in previous detraining-related studies in athletes attributed to muscular and neural factors $[42,43]$. Since previous trials have been showing that reduced leg-muscle strength was associated with lower outcomes in functional capacity among hemodialysis patients $[44,45]$, it is possible that the loss of strength due to long-term detrained accounted for the decreased physical component of QoL observed in the present study. Nevertheless, other parameters affecting muscle mass such as sleep quality has been associated with impaired functional capacity among hemodialysis patients [46].

The findings of the current study expose the detrimental effect of detraining in QoL-related parameters in patients receiving hemodialysis therapy. In particular, the total score of QoL and sleep quality significant decreased by $19 \%$ and $47 \%$ respectively. Furthermore, the daytime sleepiness increased significantly by $69 \%$ after 12 months of detraining implying deterioration of the overall sleep quality. Additionally, mental health aspects such as vitality, social functioning and role emotional decreased as well by $10 \%$.

It is known that fatigue is one of the most common symptoms reported by hemodialysis patients, affecting the patients' QoL and health [47]. Generally, patients receiving hemodialysis are subject to low levels of physical activity and functional capacity which leads to generalized weakness, exercise intolerance and later in depression symptoms [47]. Furthermore, recent studies indicated that intradialytic exercise programs improved physical, functional, biological and psychological parameters which lead to the progressive increase of vitality and overall QoL $[48,49]$. On the contrary, the interruption of any systematic exercise training, leads to loss of the improvements obtained throughout exercise intervention including health-related QoL as it is clearly presented in the current study. However, our data are in contrast with the findings of a 10 months detraining pilot study in the same population where QoL did not change significantly [18].

Hemodialysis patients confront different tensional factors such as family problems, depression, severe fatigue, social exclusion, unemployment, psychosocial factors and threaten to death which leads this population to high level 
of depression [50-52]. However, it is consensus in the literature that exercise have beneficial physical and psychological effects on patients under hemodialysis as one of the accessory therapeutic methods [53, 54]. Yet, in our study, parameters such fatigue and depression showed small downward changes with no statistically significance after 12-months detraining. A potential reason for the lack of observed effects on fatigue and depression scale after 12 months detraining is that some of the patients after experiencing the benefits of an exercise training program continue to have a physicallyactive lifestyle without participating in a training schedule. It seems that the everyday physical activity protects the patients from the negative effects of detraining in aspects related to mental health.

In the current study, it is necessary to point out some strengths and weaknesses. This is the first study to assess the impact of a detraining period on HD patients' functional capacity and quality of life. An additional strength is the use of gold standard methodology including a battery of functional tests and validated questionnaires. On the other hand, one of the major limitations of this study is the inability to assess body composition and other health-related parameters such as blood lipids to indicate the effect of detraining in these parameters. In addition, physiological indices of cardiorespiratory fitness derived by an incremental test using gas-analyzers could give us an indication about the effect of detraining in this parameter also. In addition, the lack of the pre-12 months training data is an important limitation of the study making the comparison between "pre training baseline" and "post detraining time point" unfeasible. Another strong limitation is that the current study design lacks an untrained control group that it would have helped better assessing the impact of detraining in patients overall physical capacity. However, limited evidence exists in the literature about the effects of detraining from a systematic intradialytic exercise training program which affect aspects of health-related QoL in patients receiving hemodialysis therapy and therefore we are plausible to believe that the outcomes of the current study bears of high significance.

In conclusion, this study enhances the importance of maintaining a high fitness level either by a physically-active life style or participating in a systematic exercise training program in patients receiving hemodialysis therapy. Absence of systematic physical activity for 12 months could result in significant losses in functional capacity and reductions in health-related quality of life parameters. Future studies should assess the effect of detraining in physiological and biochemical parameters which are closely related to health and quality of care in patients receiving hemodialysis therapy.

Acknowledgements We would like to thank, the nursing staff at the hemodialysis unit of the General Hospital of Trikala for their cooperation, and all hemodialysis patients for participating in this study.

Funding There is no funding source.

\section{Compliance with ethical standards}

Conflict of interest The authors declare that they have no conflicts of interest.

\section{References}

1. Levey AS, Coresh J (2012) Chronic kidney disease. Lancet 379(9811):165-180. https://doi.org/10.1016/S0140 -6736(11)60178-5

2. Cheema BSB, Singh MAF (2005) Exercise training in patients receiving maintenance hemodialysis: a systematic review of clinical trials. Am J Nephrol 25(4):352-364. https://doi. org/10.1159/000087184

3. Kalantar-Zadeh K, Kopple JD, Block G, Humphreys MH (2001) Association among SF36 quality of life measures and nutrition, hospitalization, and mortality in hemodialysis. J Am Soc Nephrol 12(12):2797-2806

4. Giannaki CD, Hadjigavriel M, Lazarou A, Michael A, Damianou L, Atmatzidis E, Stefanidis I, Hadjigeorgiou GM, Sakkas GK, Pantzaris M (2017) Restless legs syndrome is contributing to fatigue and low quality of life levels in hemodialysis patients. World J Nephrol 6(5):236-242. https://doi.org/10.5527/wjn. v6.i5.236

5. Koufaki P, Greenwood S, Painter P, Mercer T (2015) The BASES expert statement on exercise therapy for people with chronic kidney disease. J Sports Sci 33(18):1902-1907. https://doi. org/10.1080/02640414.2015.1017733

6. Koufaki P, Kouidi E (2010) Current best evidence recommendations on measurement and interpretation of physical function in patients with chronic kidney disease. Sports Med 40(12):10551074. https://doi.org/10.2165/11536880-000000000-00000

7. Giannaki CD, Hadjigeorgiou GM, Karatzaferi C, Maridaki MD, Koutedakis Y, Founta P, Tsianas N, Stefanidis I, Sakkas GK (2013) A single-blind randomized controlled trial to evaluate the effect of 6 months of progressive aerobic exercise training in patients with uraemic restless legs syndrome. Nephrol Dial Transpl 28(11):2834-2840. https://doi.org/10.1093/ndt/gft288

8. Giannaki CD, Sakkas GK, Karatzaferi C, Hadjigeorgiou GM, Lavdas E, Kyriakides T, Koutedakis Y, Stefanidis I (2013) Effect of exercise training and dopamine agonists in patients with uremic restless legs syndrome: a six-month randomized, partially double-blind, placebo-controlled comparative study. BMC Nephrol 14(1):194. https://doi.org/10.1186/1471-2369-14-194

9. Greenwood SA, Lindup H, Taylor K, Koufaki P, Rush R, Macdougall IC, Mercer TH (2012) Evaluation of a pragmatic exercise rehabilitation programme in chronic kidney disease. Nephrol Dial Transpl 27(3):126-134. https://doi.org/10.1093/ndt/gfs272

10. Greenwood SA, Naish P, Clark R, O'Connor E, Pursey VA, Macdougall IC, Mercer TH, Koufaki P (2014) Intra-dialytic exercise training: a pragmatic approach. J Ren Care 40(3):219-226. https ://doi.org/10.1111/jorc.12080

11. Painter P, Johansen KL (2006) Improving physical functioning: time to be a part of routine care. Am J Kidney Dis 48(1):167-170

12. Sakkas GK, Hadjigeorgiou GM, Karatzaferi C, Maridaki MD, Giannaki CD, Mertens PR, Rountas C, Vlychou M, Liakopoulos V, Stefanidis I (2008) Intradialytic aerobic exercise training ameliorates symptoms of restless legs syndrome and improves 
functional capacity in patients on hemodialysis: a pilot study. ASAIO J 54(2):185-190. https://doi.org/10.1097/MAT.0b013 e3181641b07

13. Kouidi E (2004) Health-related quality of life in end-stage renal disease patients: the effects of renal rehabilitation. Clin Nephrol 61(Suppl 1):S60-71

14. Sakkas GK, Giannaki CD, Karatzaferi C, Maridaki M, Koutedakis Y, Hadjigeorgiou GM, Stefanidis I (2015) Current trends in the management of uremic restless legs syndrome: a systematic review on aspects related to quality of life, cardiovascular mortality and survival. Sleep Med Rev 21:39-49. https://doi. org/10.1016/j.smrv.2014.07.006

15. Kontos PC, Miller KL, Brooks D, Jassal SV, Spanjevic L, Devins GM, De Souza MJ, Heck C, Laprade J, Naglie G (2007) Factors influencing exercise participation by older adults requiring chronic hemodialysis: a qualitative study. Int Urol Nephrol 39(4):13031311. https://doi.org/10.1007/s11255-007-9265-Z

16. Jhamb M, McNulty ML, Ingalsbe G, Childers JW, Schell J, Conroy MB, Forman DE, Hergenroeder A, Dew MA (2016) Knowledge, barriers and facilitators of exercise in dialysis patients: a qualitative study of patients, staff and nephrologists. BMC Nephrol 17(1):192. https://doi.org/10.1186/s12882-016-0399-z

17. Michou V, Kouidi E, Liakopoulos V, Dounousi E, Deligiannis A (2019) Attitudes of hemodialysis patients, medical and nursing staff towards patients' physical activity. Int Urol Nephrol 51(7):1249-1260. https://doi.org/10.1007/s11255-019-02179-1

18. Gravina EPL, Pinheiro BV, da Silva Jesus LA, da Silva LP, da Silva RN, Silva K, de Paula RB, Reboredo MM (2019) Effects of long-term aerobic training and detraining on functional capacity and quality of life in hemodialysis patients: a pilot study. Int J Artif Organs. https://doi.org/10.1177/0391398819890622

19. Ware JE Jr (2000) SF-36 health survey update. Spine 25(24):3130-3139

20. Johns MW (1991) A new method for measuring daytime sleepiness: the Epworth sleepiness scale. Sleep 14(6):540-545

21. Zung WW (1965) A self-rating depression scale. Arch Gen Psychiatry $12: 63-70$

22. Buysse DJ, Reynolds CF 3rd, Monk TH, Berman SR, Kupfer DJ (1989) The Pittsburgh Sleep Quality Index: a new instrument for psychiatric practice and research. Psychiatry Res 28(2):193-213

23. Krupp LB, LaRocca NG, Muir-Nash J, Steinberg AD (1989) The fatigue severity scale. Application to patients with multiple sclerosis and systemic lupus erythematosus. Arch Neurol 46(10):1121-1123

24. Koufaki P, Mercer T (2009) Assessment and monitoring of physical function for people with CKD. Adv Chronic Kidney Dis 16(6):410-419. https://doi.org/10.1053/j.ackd.2009.08.010

25. Giannaki CD, Sakkas GK, Karatzaferi C, Hadjigeorgiou GM, Lavdas E, Liakopoulos V, Tsianas N, Koukoulis GN, Koutedakis Y, Stefanidis I (2011) Evidence of increased muscle atrophy and impaired quality of life parameters in patients with uremic restless legs syndrome. PLoS ONE 6(10):e25180. https://doi.org/10.1371/ journal.pone.0025180

26. Kouidi E, Albani M, Natsis K, Megalopoulos A, Gigis P, GuibaTziampiri O, Tourkantonis A, Deligiannis A (1998) The effects of exercise training on muscle atrophy in haemodialysis patients. Nephrol Dial Transpl 13(3):685-699

27. Roberts CK, Barnard RJ (2005) Effects of exercise and diet on chronic disease. J Appl Physiol 98(1):3-30

28. Sung YC, Liao YH, Chen CY, Chen YL, Chou CC (2017) Acute changes in blood lipid profiles and metabolic risk factors in collegiate elite taekwondo athletes after short-term de-training: a prospective insight for athletic health management. Lipids Health Dis 16(1):143. https://doi.org/10.1186/s12944-017-0534-2

29. Mujika I, Padilla S (2001) Cardiorespiratory and metabolic characteristics of detraining in humans. Med Sci Sports Exerc
33(3):413-421. https://doi.org/10.1097/00005768-20010 3000-00013

30. Ried-Larsen M, Aarts HM, Joyner MJ (2017) Effects of strict prolonged bed rest on cardiorespiratory fitness: systematic review and meta-analysis. J Appl Physiol 123(4):790-799. https ://doi.org/10.1152/japplphysiol.00415.2017

31. Williams D, Kuipers A, Mukai C, Thirsk R (2009) Acclimation during space flight: effects on human physiology. CMAJ 180(13):1317-1323. https://doi.org/10.1503/cmaj.090628

32. Andersen JL, Aagaard P (2000) Myosin heavy chain IIX overshoot in human skeletal muscle. Muscle Nerve 23(7):1095-1104. https://doi.org/10.1002/1097-4598(20000 7) 23:7<1095:aid-mus13>3.0.co;2-o

33. Granata C, Oliveira RS, Little JP, Renner K, Bishop DJ (2016) Mitochondrial adaptations to high-volume exercise training are rapidly reversed after a reduction in training volume in human skeletal muscle. FASEB J 30(10):3413-3423. https:// doi.org/10.1096/fj.201500100R

34. Simsolo RB, Ong JM, Kern PA (1993) The regulation of adipose tissue and muscle lipoprotein lipase in runners by detraining. J Clin Invest 92(5):2124-2130. https://doi.org/10.1172/JCI11 6813

35. Reutter-Bernays D, Rentsch HP (1993) Rehabilitation of the elderly patient with stroke: an analysis of short-term and long-term results. Disabil Rehabil 15(2):90-95. https://doi. org/10.3109/09638289309165877

36. Toraman NF, Ayceman N (2005) Effects of six weeks of detraining on retention of functional fitness of old people after nine weeks of multicomponent training. Br J Sports Med 39(8):565-568. https ://doi.org/10.1136/bjsm.2004.015586

37. Wadell K, Henriksson-Larsen K, Lundgren R, Sundelin G (2005) Group training in patients with COPD long-term effects after decreased training frequency. Disabil Rehabil 27(10):571-581. https://doi.org/10.1080/09638280400018627

38. Douda HT, Kosmidou KV, Smilios I, Volaklis KA, Tokmakidis SP (2015) Community-based training-detraining intervention in older women: a five-year follow-up study. J Aging Phys Act 23(4):496-512. https://doi.org/10.1123/japa.2013-0241

39. Mustata S, Chan C, Lai V, Miller JA (2004) Impact of an exercise program on arterial stiffness and insulin resistance in hemodialysis patients. J Am Soc Nephrol 15(10):2713-2718. https://doi. org/10.1097/01.ASN.0000140256.21892.89

40. Williams PT, Thompson PD (2006) Dose-dependent effects of training and detraining on weight in 6406 runners during 7.4 years. Obesity (Silver Spring) 14(11):1975-1984. https://doi. org/10.1038/oby.2006.231

41. Teixeira-Salmela LF, Santiago L, Lima RC, Lana DM, Camargos FF, Cassiano JG (2005) Functional performance and quality of life related to training and detraining of community-dwelling elderly. Disabil Rehabil 27(17):1007-1012. https://doi.org/10.1080/09638 280500030688

42. Mujika I, Padilla S (2000) Detraining: loss of training-induced physiological and performance adaptations. Part I: short term insufficient training stimulus. Sports Med 30(2):79-87. https:// doi.org/10.2165/00007256-200030020-00002

43. Mujika I, Padilla S (2000) Detraining: loss of training-induced physiological and performance adaptations. Part II: long term insufficient training stimulus. Sports Med 30(3):145-154. https ://doi.org/10.2165/00007256-200030030-00001

44. Johansen KL, Shubert T, Doyle J, Soher B, Sakkas GK, KentBraun JA (2003) Muscle atrophy in patients receiving hemodialysis: effects on muscle strength, muscle quality, and physical function. Kidney Int 63(1):291-297. https://doi.org/10.104 6/j.1523-1755.2003.00704.x

45. Parsons TL, King-Vanvlack CE (2009) Exercise and end-stage kidney disease: functional exercise capacity and cardiovascular 
outcomes. Adv Chronic Kidney Dis 16(6):459-481. https://doi. org/10.1053/j.ackd.2009.08.009

46. Sakkas GK, Liakopoulos V, Karatzaferi C, Stefanidis I (2008) Sleep quality and dialysis efficacy affect functional capacity in patients receiving haemodialysis therapy. Nephrol Dial Transplant 23(8):2703-2704. https://doi.org/10.1093/ndt/gfn048

47. Sakkas GK, Karatzaferi C (2012) Hemodialysis fatigue: just "simple" fatigue or a syndrome on its own right? Front Physiol 3:306. https://doi.org/10.3389/fphys.2012.00306

48. Johansen KL, Painter P (2012) Exercise in individuals with CKD. Am J Kidney Dis 59(1):126-134. https://doi.org/10.1053/j. ajkd.2011.10.008

49. Yee J (2009) Exercise in CKD: work it out. Adv Chronic Kidney Dis 16(6):405-406. https://doi.org/10.1053/j.ackd.2009.08.007

50. Kimmel PL (2001) Psychosocial factors in dialysis patients. Kidney Int 59(4):1599-1613. https://doi.org/10.104 6/j.1523-1755.2001.0590041599.x

51. Kimmel PL (2005) Psychosocial factors in chronic kidney disease patients. Semin Dial 18(2):71-72. https://doi.org/10.1111/j.1525139X.2005.18202.x
52. Chan R, Steel Z, Brooks R, Heung T, Erlich J, Chow J, Suranyi M (2011) Psychosocial risk and protective factors for depression in the dialysis population: a systematic review and metaregression analysis. J Psychosom Res 71(5):300-310. https://doi. org/10.1016/j.jpsychores.2011.05.002

53. Mitrou GI, Grigoriou SS, Konstantopoulou E, Theofilou P, Giannaki CD, Stefanidis I, Karatzaferi C, Sakkas GK (2013) Exercise training and depression in ESRD: a review. Semin Dial 26(5):604-613. https://doi.org/10.1111/sdi.12112

54. Gerogianni G, Babatsikou F, Polikandrioti M, Grapsa E (2019) Management of anxiety and depression in haemodialysis patients: the role of non-pharmacological methods. Int Urol Nephrol 51(1):113-118. https://doi.org/10.1007/s11255-018-2022-7

Publisher's Note Springer Nature remains neutral with regard to jurisdictional claims in published maps and institutional affiliations. 